\title{
Effect of Loading Speed on the Mechanical Properties of Nail Joints
}

\author{
Shervin Shameli Derakshan ${ }^{1 *}$, Lina Zhou ${ }^{2}$, and Chun $\mathrm{Ni}^{3}$ \\ ${ }^{1}$ Ph.D. Student, Department of Civil Engineering, University of Victoria \\ ${ }^{2}$ Assistant Professor, Department of Civil Engineering, University of Victoria \\ ${ }^{3}$ Principle Scientist, Advanced Building Systems, FPInnovations \\ *Corresponding author's e-mail: shshameli@uvic.com
}

\begin{abstract}
Wood shear walls are the main lateral load resisting systems in light wood frame buildings to resist the wind and seismic loads. Sheathing to lumber nail connections are regarded as the key components that control the resistance and failure modes of wood shear walls. Considerable experimental tests have been conducted on performance of nail joints or wood shear walls under both static and reversed cyclic loads. However, these tests were usually conducted under different loading speed causing specimen failure in $1 \mathrm{~min}$ to an hour. It is unclear how the loading speed will affect the test results of nail joints or wood shear walls. Research on these topics is limited. This paper aims to evaluate the effect of loading speed on the mechanical characteristics of nail joints. 72 specimens have been tested under various loading speeds, ranging from $0.05 \mathrm{~mm} / \mathrm{s}$ to $0.5 \mathrm{~mm} / \mathrm{s}$ for monotonic tests and $1.5 \mathrm{~mm} / \mathrm{s}$ to $15 \mathrm{~mm} / \mathrm{s}$ for reversed cyclic tests. The range of loading speed was selected based on the total estimated loading time that both monotonic and reversed cyclic tests fail within around $1 \mathrm{~min}$ to $10 \mathrm{~min}$. Two groups of nail joints, comprising two common nail sizes and two sheathing thicknesses, were assessed under both monotonic and reversed cyclic loads. From the test results, the effect of loading speed on the mechanical properties of nail joints was determined.
\end{abstract}

\section{KEYWORDS}

Loading speed; Nail joint; Monotonic load; Reversed cyclic load

\section{INTRODUCTION}

Light wood frame buildings are the most predominant construction style for low-rise residential buildings in North America. It has been become increasingly popular due to the advantages of this type of construction, such as the use of naturally renewable and environmentally friendly material, high strength to weight ratio, and the possibility of offsite construction. Since 2009, residential buildings up to six stories have been permitted to be constructed in the province of British Columbia in Canada. The recent focus on climate change and energy consumption issues herald a promising future for light wood frame construction as it emits less greenhouse gas, releases less pollution and produces less solid waste compared to steel and concrete construction (CWC, 2010). When these buildings are constructed in seismically active zones, seismic design and construction methods become crucial. Wood shear walls are the primary lateral load resisting system for this type of buildings. They are composed of studs, sheathing panels, and nail 
connections. The in-plane lateral load resistant capacity is mainly provided by the sheathing panels through the sheathing-to-frame connections. Nail joints primarily contribute to energy dissipation while withstanding earthquake (Mulder, 2017). Numerous experimental studies have been conducted to explore the effect of various parameters on the seismic performance of light wood frame shear walls, such as the effect of the location of shear walls in the assembly (Nelson et al., 1985), types and sizes of fasteners (Karacabeyli et al., 1996), types and sizes of sheathing panels and the presence of opening in shear wall panels (Lam et al., 1997, Durham et al., 2001, Dolan et al., 1998, and He et al., 1999). However, these tests were usually conducted under different loading speeds causing specimen failure in $1 \mathrm{~min}$ to an hour. It is unclear how the loading speed will affect the test results of nail joints or wood shear walls, which raises questions such as whether or not the test results from these previous researches under different loading speeds can be directly used for comparisons without a need of considering the effect of loading speed. The test speed of wood shear walls suggested by ASTM E2126 (ASTM 2011) under reversed cyclic load covers a large range from 1.0 to $63.5 \mathrm{~mm} / \mathrm{s}$. While ASTM doesn't provide testing standards for nail joints under revised cyclic load, research on these topics is limited.

Girhammar et al. (1988) investigated the effect of loading speed on yield strength of four types of timber joints under monotonic load along both parallel and perpendicular to the grain direction. All of the tests were conducted on double-shear nail joints, and the loading speed varied from $2 \mathrm{~mm} / \mathrm{min}$ to $21 \mathrm{~mm} / \mathrm{min}$. The experiments revealed that the effect of loading speed on bearing strength of wood was more significant than its effect on yield strength of nails. In most cases, the increase in loading speed led to lower peak loads. Furthermore, they pointed out that the growth of ultimate load was linearly related to the logarithmic speed rate. These tests were conducted on the joints with similar width of wood elements and no reversed-cyclic load tests were performed.

In this study, the effect of loading speed on the mechanical characteristics of nail joints was investigated through experimental tests. Single-shear nail joints with two different nail sizes and two different sheathing thicknesses have been tested under both monotonic and reversed cyclic load. Loading speeds were chosen in a way that specimens would fail in a time period from 1 to 10 minutes.

\section{Materials and Methods}

There were 72 specimens of single shear nail joints being tested in this study. Each specimen consisted of $2 \times 4$ Spruce-Pine-Fir (SPF) dimensional lumber and OSB panel. The OSB panel was fastened to the stud by two nails. The two nail types used in the joints were common nail $8 \mathrm{~d}$ with a shank length of $63.5 \mathrm{~mm}$ (2.5 in.) and a diameter of $3.33 \mathrm{~mm}(0.131 \mathrm{in})$, and common nail $12 \mathrm{~d}$ with a shank length of $82.55 \mathrm{~mm}$ (3.25 in) and a diameter of $3.76 \mathrm{~mm}$ (0.148 in). The two thicknesses of the OSB were $11.11 \mathrm{~mm}$ (7/16 in) and $15.08 \mathrm{~mm}$ (19/32 in). Common nail 8d was used with $11.11 \mathrm{~mm}$ (7/16 in) OSB, while common nail $12 \mathrm{~d}$ was used with $15.08 \mathrm{~mm}$ (19/32 in) OSB. Cyclic and monotonic loadings were applied to each joint configuration. The loaddisplacement curve for each group was computed by averaging the curves of six replicates. Figure 1 shows the details of side and front views of the test specimen. Two Linear Variable Differential Transformers (LVDTs) were attached to the specimen to measure the relative 
displacement between the lumber and OSB. The recorded displacements by the two LVDTs were averaged to provide mean values. Figure 2 illustrates the entire test apparatus.

Three loading speeds were used for monotonic tests: $0.05,0.1$, and $0.5 \mathrm{~mm} / \mathrm{s}$ that would make the specimens fail in around 10,5 and $1 \mathrm{~min}$, respectively by assuming an ultimate displacement of $30 \mathrm{~mm}$ under monotonic load based on trial tests. The lower boundary of $0.05 \mathrm{~mm} / \mathrm{s}$ was determined in accordance with ASTM D1761 (ASTM, 2012). The upper boundary speed was determined according to the estimated failure time of $1 \mathrm{~min}$, which represented the duration of a real earthquake. The three loading speeds for reversed cyclic load tests were estimated by assuming specimens failed in the same time as under monotonic load. As the total loading displacement of cyclic tests is much larger than that of monotonic test, the speed of reversed cyclic load chosen in this project is much higher than monotonic test. ISO 16670 loading protocol, which is widely used for light wood frame shear wall tests, was selected for reversed cyclic load test of nail joints (as shown in figure 3). Table 1 provides combination details of specimens, loading speeds and protocols. Each group has six replicates.
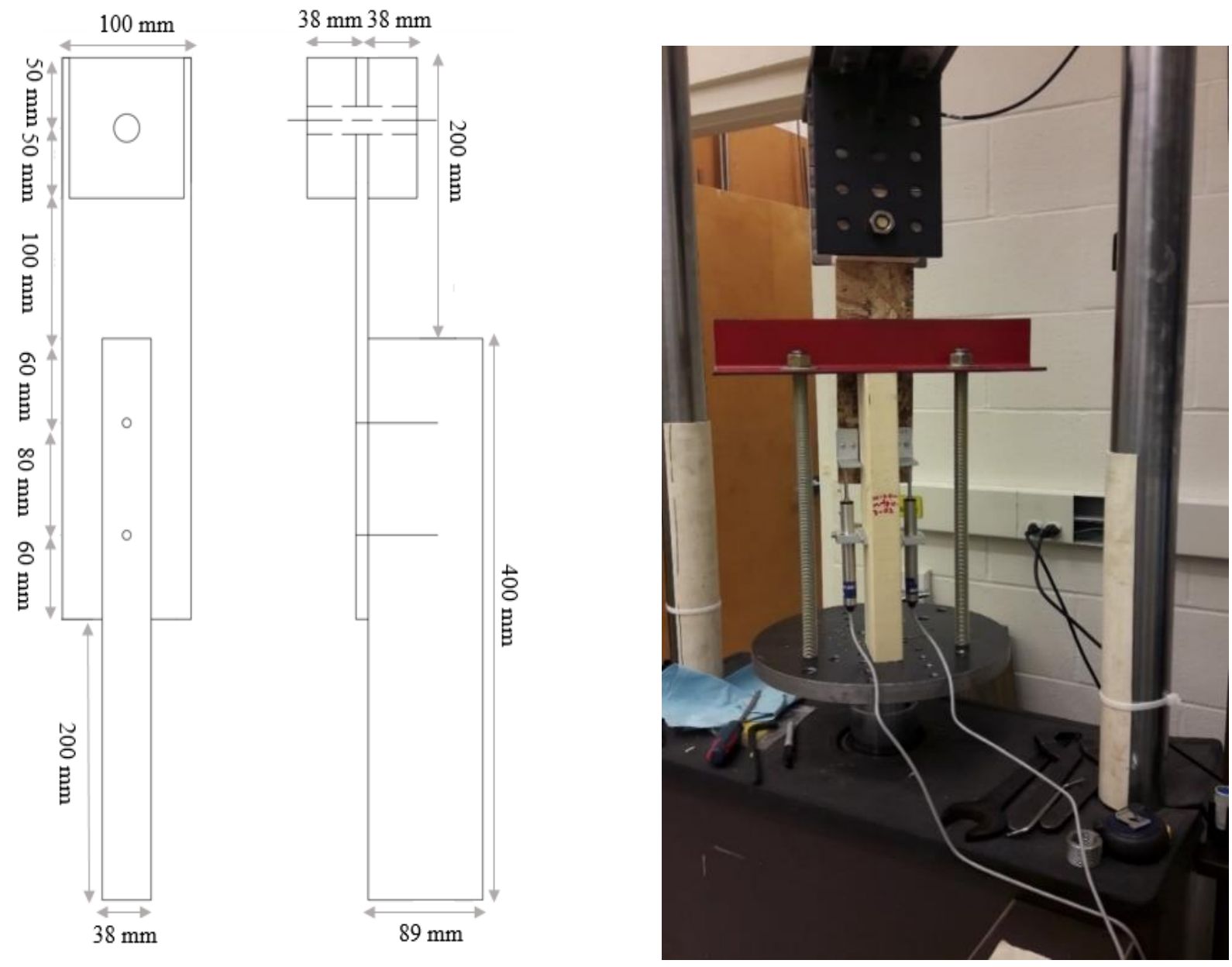

Figure 1. Side and front views of the test specimen Figure 2. Test apparatus of nail joint 
MOC SUMMIT / MAY 2019

Table 1. Test plan for monotonic and reversed-cyclic tests

\begin{tabular}{|c|c|c|c|c|c|}
\hline Group Name & $\begin{array}{l}\text { Loading } \\
\text { Protocol }\end{array}$ & $\begin{array}{c}\text { Common } \\
\text { nail size }\end{array}$ & OSB Thickness & Loading Speed & Replicate \\
\hline M8D0.05mm/s & Monotonic & $8 \mathrm{D}$ & $11 \mathrm{~mm}(7 / 16 \mathrm{in})$ & $0.05 \mathrm{~mm} / \mathrm{s}$ & 6 \\
\hline $\mathrm{M} 8 \mathrm{D} 0.1 \mathrm{~mm} / \mathrm{s}$ & Monotonic & $8 \mathrm{D}$ & $11 \mathrm{~mm}(7 / 16 \mathrm{in})$ & $0.1 \mathrm{~mm} / \mathrm{s}$ & 6 \\
\hline $\mathrm{M} 8 \mathrm{D} 0.5 \mathrm{~mm} / \mathrm{s}$ & Monotonic & $8 \mathrm{D}$ & $11 \mathrm{~mm}(7 / 16 \mathrm{in})$ & $0.5 \mathrm{~mm} / \mathrm{s}$ & 6 \\
\hline $\mathrm{M} 12 \mathrm{D} 0.05 \mathrm{~mm} / \mathrm{s}$ & Monotonic & $12 \mathrm{D}$ & $15 \mathrm{~mm}(19 / 32 \mathrm{in})$ & $0.05 \mathrm{~mm} / \mathrm{s}$ & 6 \\
\hline $\mathrm{M} 12 \mathrm{D} 0.1 \mathrm{~mm} / \mathrm{s}$ & Monotonic & $12 \mathrm{D}$ & $15 \mathrm{~mm}(19 / 32 \mathrm{in})$ & $0.1 \mathrm{~mm} / \mathrm{s}$ & 6 \\
\hline $\mathrm{M} 12 \mathrm{D} 0.5 \mathrm{~mm} / \mathrm{s}$ & Monotonic & $12 \mathrm{D}$ & $15 \mathrm{~mm}(19 / 32 \mathrm{in})$ & $0.5 \mathrm{~mm} / \mathrm{s}$ & 6 \\
\hline $\mathrm{C} 8 \mathrm{D} 1.5 \mathrm{~mm} / \mathrm{s}$ & Cyclic & $8 \mathrm{D}$ & $11 \mathrm{~mm}(7 / 16 \mathrm{in})$ & $1.5 \mathrm{~mm} / \mathrm{s}$ & 6 \\
\hline $\mathrm{C} 8 \mathrm{D} 3 \mathrm{~mm} / \mathrm{s}$ & Cyclic & $8 \mathrm{D}$ & $11 \mathrm{~mm}(7 / 16 \mathrm{in})$ & $3 \mathrm{~mm} / \mathrm{s}$ & 6 \\
\hline $\mathrm{C} 8 \mathrm{D} 15 \mathrm{~mm} / \mathrm{s}$ & Cyclic & $8 \mathrm{D}$ & $11 \mathrm{~mm}(7 / 16 \mathrm{in})$ & $15 \mathrm{~mm} / \mathrm{s}$ & 6 \\
\hline $\mathrm{C} 12 \mathrm{D} 1.5 \mathrm{~mm} / \mathrm{s}$ & Cyclic & $12 \mathrm{D}$ & $15 \mathrm{~mm}(19 / 32 \mathrm{in})$ & $1.5 \mathrm{~mm} / \mathrm{s}$ & 6 \\
\hline $\mathrm{C} 12 \mathrm{D} 3 \mathrm{~mm} / \mathrm{s}$ & Cyclic & $12 \mathrm{D}$ & $15 \mathrm{~mm}(19 / 32 \mathrm{in})$ & $3 \mathrm{~mm} / \mathrm{s}$ & 6 \\
\hline $\mathrm{C} 12 \mathrm{D} 15 \mathrm{~mm} / \mathrm{s}$ & Cyclic & $12 \mathrm{D}$ & $15 \mathrm{~mm}$ (19/32 in) & $15 \mathrm{~mm} / \mathrm{s}$ & 6 \\
\hline
\end{tabular}

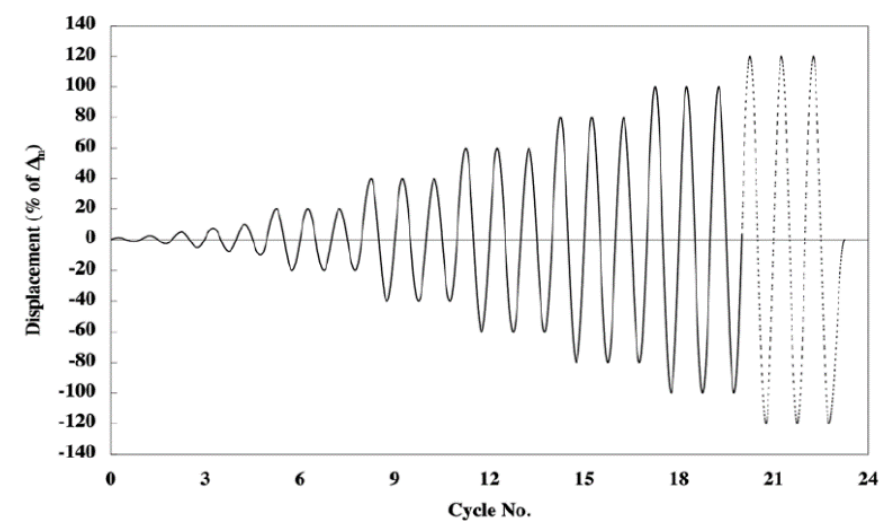

Figure 3. ISO 16670 Loading Protocol (ASTM, 2011)

\section{Results and Discussion}

The load-displacement curves of nail joints under monotonic load are shown in Figure 4 (a). As noted previously, each curve in Figure 4 represents the average load-displacement curves of the six replicates of a single nail joint. For reversed-cyclic tests, backbone curves were plotted by finding the peak values of loads and the relative displacement in each cycle for both positive and negative loops as described in ASTM E2126 (ASTM, 2011). Figure 5 shows an example of the hysteresis curve and the peak points in each cycle, which constitute the envelope curve. The final backbone curve of a nail joint is the average of the positive and negative loops. Figure 4 (b) illustrates averaged backbone curves for each test group. As expected, the group with thicker OSB panel and larger size of nails resulted in stronger nail joint connection under both monotonic and reversed cyclic load. Moreover, Figure 4 (a) reveals that all groups of nail joints experienced similar ultimate deformation under monotonic loading, except for M12D0.5mm/s. 
Figure 6 shows the comparison of the tests under monotonic and reversed cyclic load. The monotonic curve agrees well with the cyclic curve before the peak load, except for the case of M8D0.05mm/s and C8D1.5mm/s. After the peak load, the backbone curve of cyclic test drops faster than the monotonic curve, which leads to a relatively smaller ultimate displacement, except that in the case of M12D $0.05 \mathrm{~mm} / \mathrm{s}$ and $\mathrm{C} 12 \mathrm{D} 1.5 \mathrm{~mm} / \mathrm{s}$, no obvious differences are observed between monotonic and reversed cyclic tests (Figure 5).

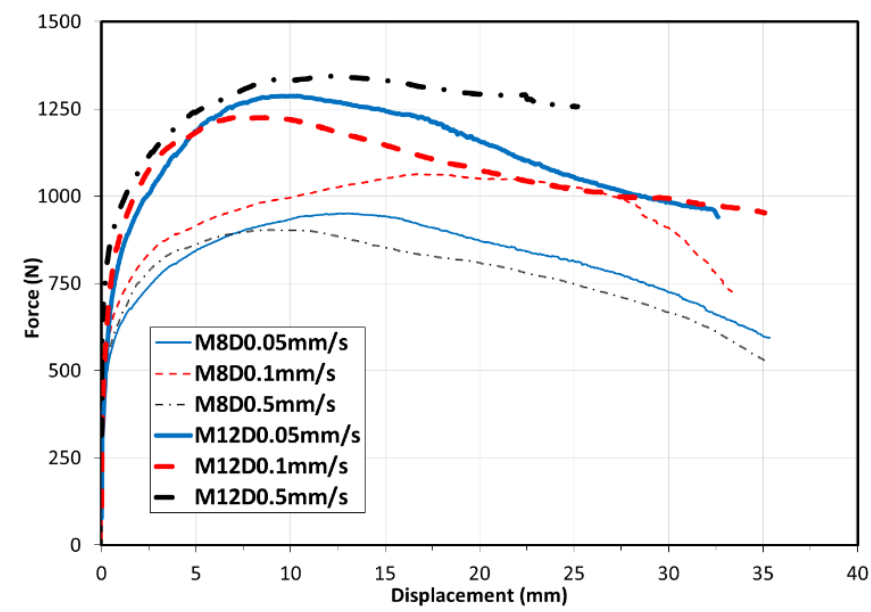

(a) Monotonic loading

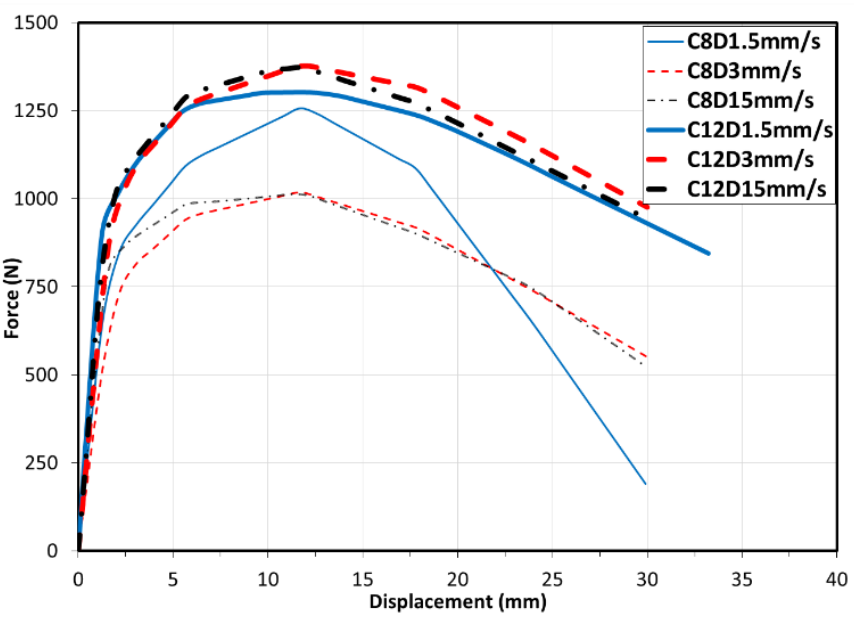

(b) Reversed-cyclic loading

Figure 4. Load-displacement curves of nail joints

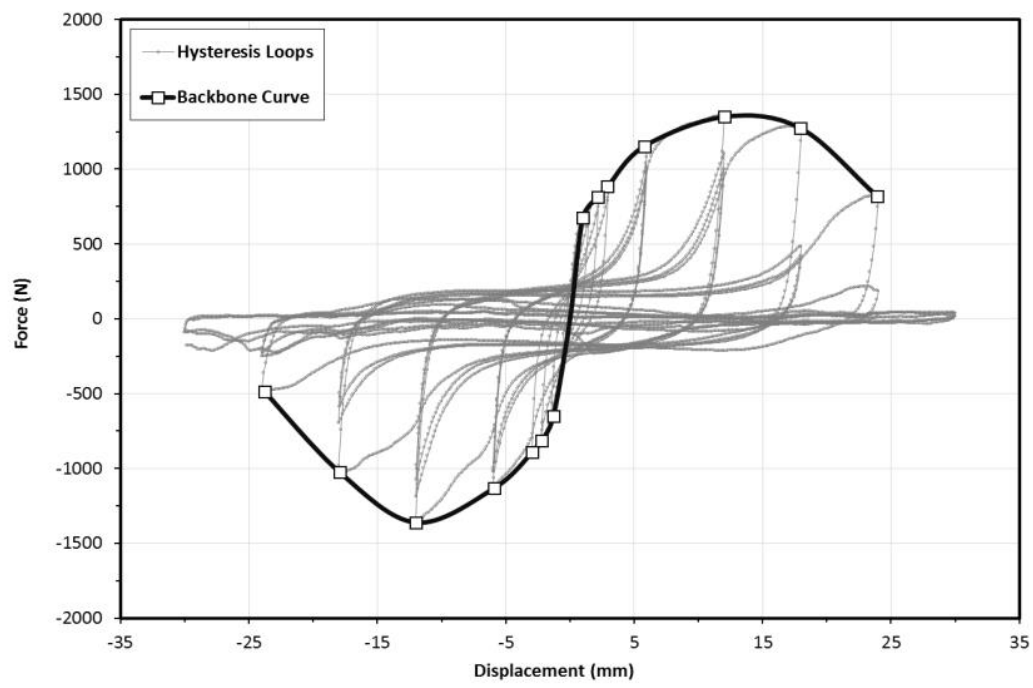

Figure 5. Hysteresis curve and its envelope curve for C8D1.5mm/s 
Mechanical properties of nail joint under monotonic and reversed-cyclic loads were obtained by using Equivalent Energy Elastic-Plastic (EEEP) curves in accordance with ASTM E2126 (ASTM, 2011). Table 2 compares mechanical properties of nail joints for monotonic and reversed-cyclic loading tests. $K$ is the elastic shear stiffness derived by dividing $0.4 F_{\text {peak }}$ by the corresponding displacement. $\Delta_{u}$ is the ultimate displacement: a point at which the bearing load declines to $0.8 F_{\text {peak }} . \mu$ is the ductility ratio, which is the ratio of ultimate displacement to yield displacement expressed in the EEEP curves. 

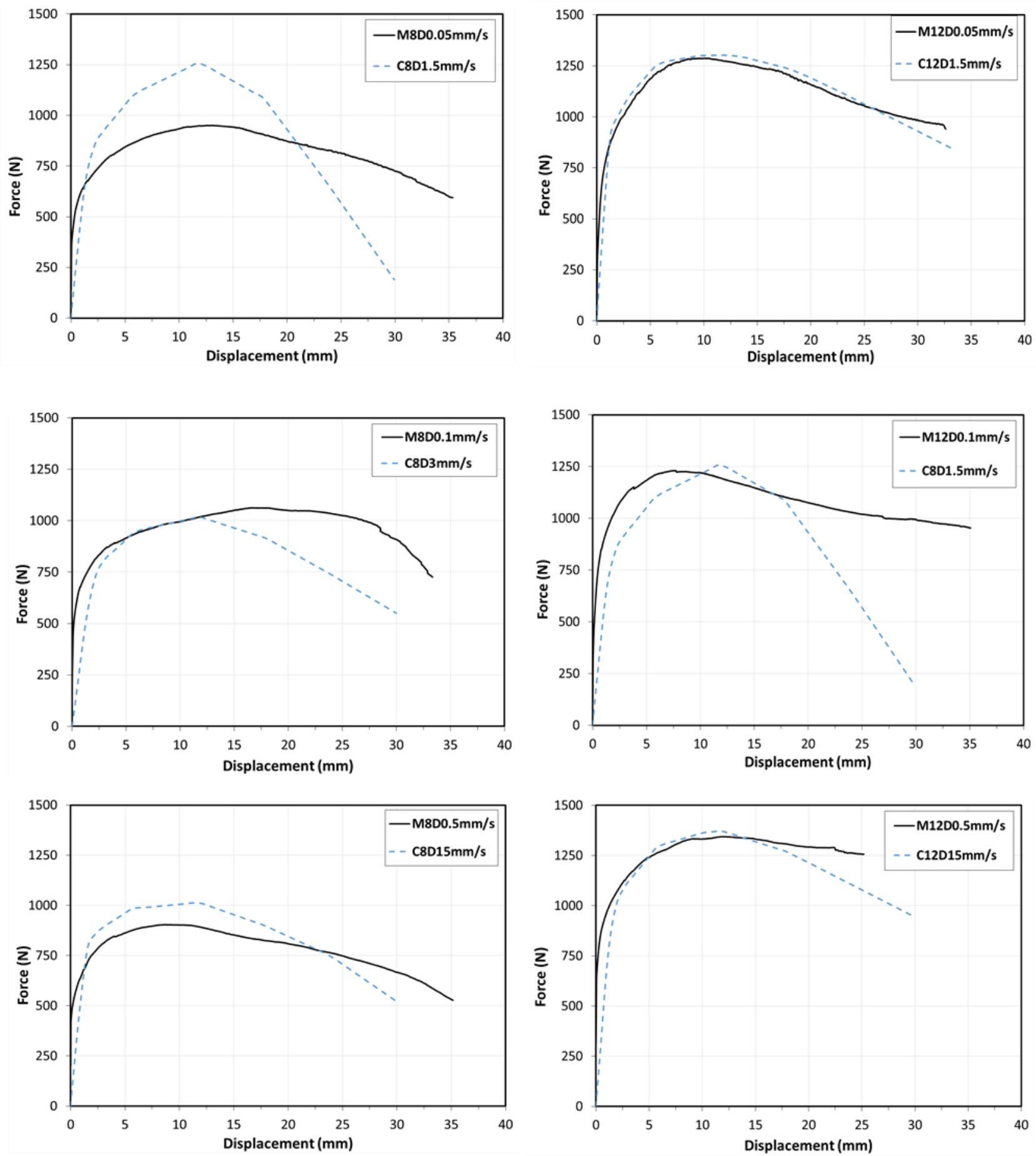

Figure 6. Comparison of load-displacement curves under monotonic and reversed cyclic load

Table 2. Mechanical properties of the tested nail joints

\begin{tabular}{ccccccc} 
Group Name & $F_{\text {peak }}(K \mathrm{~N})$ & Difference of $F_{\text {peak }}$ & $K(\mathrm{KN} / \mathrm{mm})$ & $\mu$ & $\Delta_{u}(\mathrm{~mm})$ & Difference of $\Delta_{u}$ \\
\hline M8D0.05mm/s & 0.95 & - & 5.438 & 7.1 & 28.3 & - \\
M8D0.1 mm/s & 1.063 & $12 \%^{1}$ & 4.918 & 46.9 & 31.2 & $10 \%$ \\
M8D0.5mm/s & 0.904 & $-5 \%$ & 22.385 & 12.0 & 26.7 & $-6 \%$ \\
M12D0.05mm/s & 1.287 & - & 2.118 & 6.6 & 26.5 & -
\end{tabular}


MOC SUMMIT / MAY 2019

\begin{tabular}{ccccccc}
$\mathrm{M} 12 \mathrm{D} 0.1 \mathrm{~mm} / \mathrm{s}$ & 1.230 & $-4 \%$ & 3.525 & 14.2 & 31.1 & $17 \%$ \\
$\mathrm{M} 12 \mathrm{D} 0.5 \mathrm{~mm} / \mathrm{s}$ & 1.343 & $4 \%$ & 15.658 & 8.6 & 25.1 & $-5 \%$ \\
$\mathrm{C} 8 \mathrm{D} 1.5 \mathrm{~mm} / \mathrm{s}$ & 1.256 & - & 0.514 & 3.6 & 18.9 & - \\
$\mathrm{C} 8 \mathrm{D} 3 \mathrm{~mm} / \mathrm{s}$ & 1.017 & $-19 \%$ & 0.401 & 5.2 & 21.4 & $13 \%$ \\
$\mathrm{C} 8 \mathrm{D} 15 \mathrm{~mm} / \mathrm{s}$ & 1.013 & $-19 \%$ & 0.574 & 9.0 & 21.4 & $13 \%$ \\
$\mathrm{C} 12 \mathrm{D} 1.5 \mathrm{~mm} / \mathrm{s}$ & 1.302 & - & 0.753 & 8.2 & 25.8 & - \\
$\mathrm{C} 12 \mathrm{D} 3 \mathrm{~mm} / \mathrm{s}$ & 1.376 & $6 \%$ & 0.567 & 6.1 & 25.7 & $0 \%$ \\
$\mathrm{C} 12 \mathrm{D} 15 \mathrm{~mm} / \mathrm{s}$ & 1.372 & $5 \%$ & $0.662 \mathrm{e}$ & 6.4 & 24.3 & $-6 \%$ \\
\hline
\end{tabular}

Notes ${ }^{1}$ : The case of smallest loading speed is used as the reference.

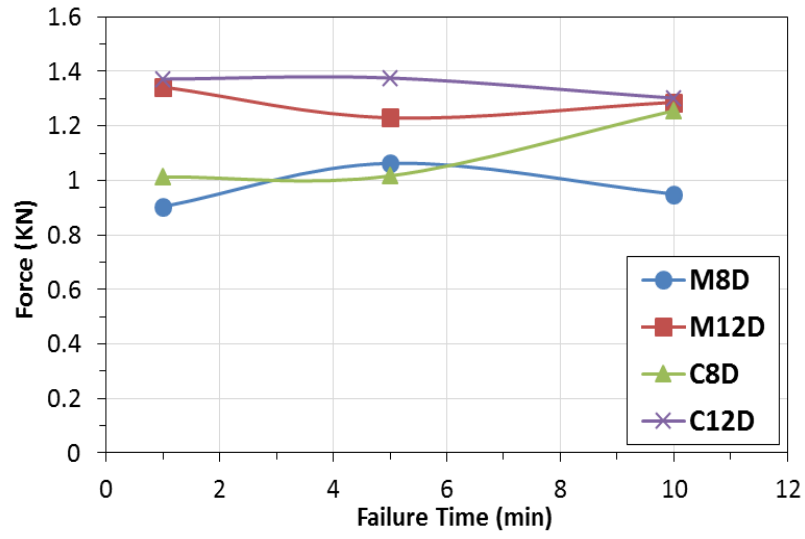

(a) Effect of loading speed on $F_{\text {peak }}$

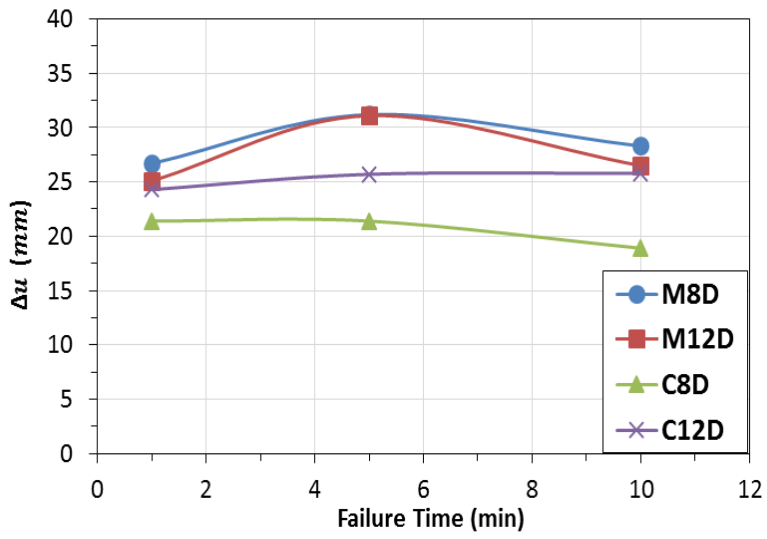

(b) Effect of loading speed on $\Delta_{u}$

Figure 7. Effect of loading speed

Figure 7 (a) and (b) show the effect of loading speed on the ultimate resistance and displacement of nail joint under both monotonic and reversed cyclic load. When the failure time decreases (i.e. the loading speed increases) the $F_{\text {peak }}$ and $\Delta_{u}$ may increase or decrease. There is no clear tendency of changes of these two parameters. The difference caused by the change of speed is within 10\% in most cases (Table 2). The large difference in groups of C8D is mainly caused by the unexpected high $F_{\text {peak }}$ of $\mathrm{C} 8 \mathrm{D} 1.5 \mathrm{~mm} / \mathrm{s}$ (Table 2). Therefore, the speed effect on the ultimate resistance and displacement of nail joint can be ignored when the specimen fails in 1 to $10 \mathrm{~min}$.

The values of stiffness and ductility vary considerably especially for the groups under monotonic load (Table 2). The maximum and minimum values of the stiffness in Table 2 undergoing monotonic and reversed cyclic load differ 54 times and 26.6 times, respectively. These huge differences can be attributed to the EEEP curve method used in ASTM E2126 (ASTM, 2011) in which the stiffness is highly sensitive to the points chosen for the linearization. ASTM E2126 (ASTM, 2011) suggests a linearization between zero point and $0.4 F_{\text {peak }}$ point for finding the stiffness. Value changes abruptly in the early time steps of the tests. Therefore, choosing neighboring points and interpolation will significantly affect the stiffness. Meanwhile, the ductility ratio, $\mu$, is sensitive to the definition of the yielding point that leads to the huge differences shown in Table 2. Generally, the stiffness and ductility values are more consistent under reversed cyclic load compared with monotonic load. 
MOC SUMMIT / MAY 2019

Regarding the values of Table 2, it can be inferred that there is no distinct correlation between loading speed and mechanical properties of nailed joints loaded with the range of studied speeds.

\section{Conclusion}

This study looked into the effect of loading speed on the mechanical properties of nail joints. A total of 72 specimens has been tested under both monotonic and reversed-cyclic loads. Various loading speeds have been considered in order to cover the range of loading speeds commonly used for testing nail joints. The results of the experiments showed that the effect of loading speed on the mechanical properties of nail joints could be ignored for a failure time range between 1 min and $10 \mathrm{~min}$. In some cases, lateral load resistance of the nail joints could be altered up to 19\%; however, a specific trend between the loading speed and mechanical properties of nail joints was not observed within the range of the investigated loading speeds.

\section{REFERENCES}

ASTM. (2012). "Standard test methods for mechanical fasteners in wood." ASTM D1761-12, West Conshohocken, PA, USA.

ASTM. (2011). "Standard test methods for cyclic (reversed) load test for shear resistance of vertical elements of the lateral force resisting systems for buildings." ASTM E2126-11, West Conshohocken, PA, USA.

Canadian Wood Council (CWC). (2010). "Energy and the environment in residential construction." Ottawa, Onterio, Canada.

Dolan, J.D., and Heine, C.P. (1998). "Cyclic response of light-framed shear walls with openings." Proc., Structural Engineering Worldwide, Paper No. T207-3, Elsevier Science, New York, USA.

Durham, J., Lam, F., and Prion, G.L. (2001). "Seismic resistance of wood shear walls with large OSB panels." Journal of Structural Engineering, 127 (12), 1460-1466.

He, M., Magnusson, H., Lam, F., and Prion, H.G.L. (1999). "Cyclic performance of perforated wood shear walls with oversize OSB panels." Journal of Structural Engineering, 125 (1), $10-18$.

Girhammar, U.A., and Hakan, A. (1988). "Effect of loading rate on nailed timber joint capacity." Journal of Structural Engineering, 114 (1).

Karacabeyli, E., and Ceccotti, A. (1998). "Nailed wood-frame shear walls for seismic loads: Test results and design considerations." Proc., Structural Engineering Worldwide, Paper No. T207-6, Elsevier Science, New York, USA.

Lam, F., Prion, H.G.L., and He, M. (1997). "Lateral resistance of wood shear walls with large sheathing panels." Journal of Structural Engineering, 123 (12), 1666-1673.

Mulder, M.J. (2017). "Numerical modeling of seismic performance of light-frame wood buildings." Master's Thesis, University of British Columbia, Canada.

Nelson, E.L., Wheat, D.L., and Fowler, D.W. (1985). "Structural behavior of wood shear wall assemblies." Journal of Structural Engineering, 111(3), 654-666. 